\title{
DNA fingerprinting of Mycobacterium tuberculosisfrom patients with and without AIDS in Rio de Janeiro
}

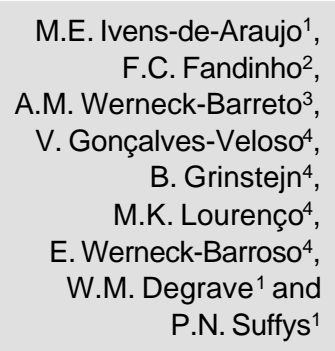

\author{
1Departamento de Bioquímica e Biologia Molecular, Instituto Oswaldo Cruz, \\ FIOCRUZ, Rio de Janeiro, RJ, Brasil \\ 2Departamento de Microbiologia, Universidade Federal de Rio de Janeiro, \\ Rio de Janeiro, RJ, Brasil \\ ${ }^{3}$ Centro de Referência Professor Hélio Fraga, Fundação Nacional de Saúde, \\ Ministério de Saúde, Rio de Janeiro, RJ, Brasil \\ ${ }^{4}$ Hospital Evandro Chagas, Instituto Oswaldo Cruz, Rio de Janeiro, RJ, Brasil
}

\section{Correspondence \\ P.N. Suffys \\ Laboratório de Biologia Molecular e \\ Diagnóstico de Doenças Infecciosas \\ Departamento de Bioquímica e \\ Biologia Molecular \\ Instituto Oswaldo Cruz, FIOCRUZ \\ Av. Brasil, 4365 \\ 21045-900 Rio de Janeiro, RJ \\ Brasil \\ Fax: 55 (021) 270-9997 \\ E-mail: \\ psuffys@gene.dbbm.fiocruz.br}

Research supported by CNPq, CABBIO, FAPERJ and PAPES.

Received June 12, 1997 Accepted January 12, 1998

\section{Abstract}

Isolates of Mycobacterium tuberculosis derived from patients with AIDS from a single hospital in Rio de Janeiro were typed using a standardized RFLP technique detecting $I S 6110$ polymorphism. Nineteen isolates were obtained from 15 different patients. Eleven distinct IS6110 patterns were found, with 4 banding patterns shared by 2 patients. The clustering value of 53\% was much higher in comparison with clustering of M. tuberculosis strains from TB patients without clinical signs for HIV infection from randomly selected health centers. We present these results as preliminary data on M. tuberculosis strain polymorphism in Brazil and on the higher risk for recent transmission amongst patients with AIDS.

It has been demonstrated that infection with HIV is a risk factor for the development of tuberculosis (TB) and this can result either from reactivating latent TB or from a newly acquired infection (1). Individual strains of Mycobacterium tuberculosis (Mtb) can be identified by molecular typing methods, and transmission of a strain throughout a community can thus be monitored (2). Increased risk for recent transmission amongst individuals with HIV has been confirmed by fingerprinting studies in outbreaks (3), in urban settings such as New York (4) and San Francisco (5), sometimes involving multidrug-resistant strains (6). The prevalence of TB in Rio de Janeiro is 140 per 100,000 inhabitants and the epidemiological situation of Brazil is different from that of African countries because TB has been endemic for centuries and, in contrast to developed countries, in Brazil, the TB epidemic never disappeared. The prevalence of PPD positivity is high and for decades now, BCG vaccination has been applied to most infants.

In contrast to TB, the HIV epidemic in Brazil has a demographic pattern similar to that observed in developed countries. Using a standardized protocol based on the detection of restriction fragment length polymorphism generated by the variation in number and position of the insertion sequence IS6110 in the bacterial genome (7), we have typed isolates of Mtb from TB patients with and without AIDS from Rio de Janeiro, Brazil. 
Deoxyribonucleic acids extracted from cultures of M. tuberculosis were digested with $P v u I I$ and internal molecular weight markers (consisting of a mixture of $\phi \mathrm{X}-\mathrm{Hae} \mathrm{III}, \lambda$ $H i n$ IIII and $P v u I I$-digested supercoiled DNA) were added to each sample. The DNA patterns were then generated and normalized by consecutive hybridization with part of IS6110 and with the internal markers labeled with the ECL direct labeling system (Amersham, UK), analyzed and stored in a computer using the GelCompar software (Applied Maths, Kortrijk, Belgium; 8).

During the period from 1993 to 1994, 57 cultures of Mtb were thus collected and analyzed; of these cultures, 38 were obtained from TB patients without clinical signs for HIV infection seen at randomly selected health centers, while 19 cultures were obtained from 15 different AIDS patients seen at the Evandro Chagas Hospital (Oswaldo Cruz Institute, RJ). Although HIV serology was not performed on TB patients from the health centers in this study, at that time, HIV positivity among TB patients from Rio de Janeiro was $11 \%$ (9). Ninety percent of the Mtb isolates had 6 to 15 copies of IS6110; only 4 strains, including 2 from patients with AIDS, had less than 6 copies, thus permitting a reliable analysis of strain similarity.

Analysis of the DNA patterns from patients with AIDS showed that two strains had the same 12-copy pattern; two more strains shared a 4-copy pattern and 4 strains had very similar patterns, with two having an identical 8-copy pattern and two more being

Figure 1 - Computer-generated dendrogram (A) and normalized IS6110 hybridization patterns (B) of strains of Mycobacterium tuberculosis isolated from eight patients with AIDS.
A
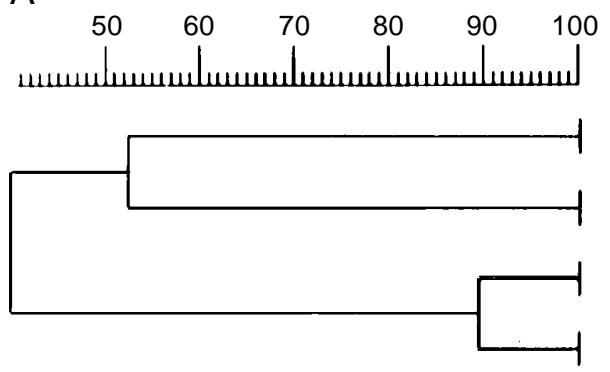

identical to the former except for two extra bands (Figure 1). Since outbreak studies have revealed that RFLP patterns with one or two extra bands are not unusual in Mtb clones (10), we inferred that the latter group could have been infected by the same or a closely related strain. Also, the four pairs of isolates that were obtained from different clinical sites of four patients with AIDS were identical (data not shown). Fifty-three percent of the Mtb strains isolated from AIDS patients frequenting the Evandro Chagas Hospital belonged to a cluster. This high level of clustering was not found in the strains isolated from the rest of the TB patients: 2 groups of 2 patients with identical strains were found, representing a clustering of only $11 \%$. Infection with identical strains among the AIDS patients could not be explained by analysis of data such as family relations, address or coincidence of residence at the hospital. However, sporadic unrecorded visits to the hospital do occur and it is known that contact in settings where HIV-infected people socialize poses a risk for transmission of TB (11).

Recent findings have pointed out that transmission of TB may not require "close and prolonged" contact as previously believed, and trivial contact in the community may be sufficient. The AIDS-TB patients studied here had previous contact with the hospital system, at least as outpatients, and although we are not exactly dealing with an outbreak situation, we suppose that these clustered infections were acquired nosoco-

B

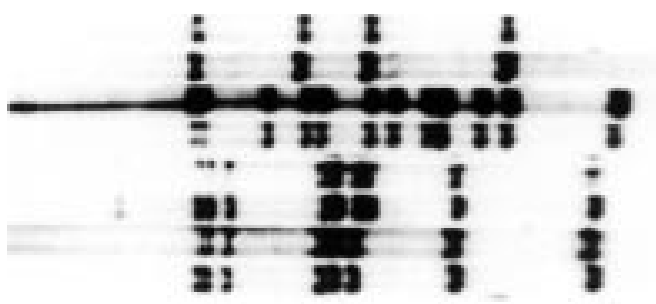


mially. This observation is very important because the standard isolation procedures for AIDS in patients with TB may not be sufficient to prevent nosocomial transmission of TB among these highly susceptible individuals. On the other hand, common exposure within the community may have been sufficient to infect this particular subpopulation. Of a total of 53 strains analyzed here, $12(22.0 \%)$ were clustered. When comparing with epidemiological data obtained with molecular markers from low prevalence countries such as the US, Switzerland and the Netherlands, as well as from high prevalence African countries (12), the level of clustering in the strains isolated from TB patients in this study is low and clustering amongst HIV-infected patients surprisingly high.

Two studies comparing strains of $M$. tuberculosis in HIV-seropositive and -seronegative patients with $\mathrm{TB}$, one performed in Tanzania (13), and the other in Italy and Pakistan (14), are contradictory. Clustering in Tanzania was independent of the patient's HIV status while the latter study demonstrated a significantly higher clustering in HIV-positive individuals. This could partly be explained by the use of different criteria for the definition of HIV status. Indeed, Small et al. (5) already demonstrated that the risk of belonging to a cluster increases with increasing immunosuppression. One of the possible reasons for the low clustering in general observed here could be that, unlike patients with AIDS, most patients were diagnosed in ambulatory services located in different neighborhoods of Rio, while in most of the other studies patient sampling occurred in one or in a small number of settings. Although AIDS and non-AIDS patients represent different neighborhoods of Rio, only patients with AIDS were treated at the same hospital. Also, the number of samples analyzed in this preliminary study is relatively small.

We are now starting a large prospective study to screen $\mathrm{TB}$ patients representing most of the city's neighborhoods. In conclusion, this study points to a large variety of TB isolates in Rio de Janeiro and demonstrates a high level of transmission of TB among AIDS patients attending a particular hospital.

\section{Acknowledgments}

We thank Dr. Afranio Kritski for helpful suggestions and Alex Almorim for artwork assistance.

\section{References}

1. Selwyn PA, Hartel D, Lewis VA, Schoenbaum EE, Vermund SH, Klein RS, Walker AT \& Friedland GH (1989). A prospective study of the risk of tuberculosis among intravenous drug users with human immunodeficiency virus infection. New England Journal of Medicine, 320: 545-550.

2. Genewein A, Telenti A, Bernasconi C, Mordasini C, Weiss S, Maurer A-M, Rieder HL, Schopfer K \& Bodmer T (1993). Molecular approach to identifying route of transmission of tuberculosis in the community. Lancet, 342: 841-844.

3. Daley CL, Small PM, Schecter GF, Schoolnik GK, McAdam RA, Jacobs WR \& Hopewell PC (1992). An outbreak of tuberculosis with accelerated progression among persons infected with the human immunodeficiency virus. New England Journal of Medicine, 326: 231-235.

4. Allend D, Kalkut GF, Moss AR, McAdam RA, Hahn JA, Bosworth W, Drucker E \& Bloom BR (1994). Transmission of tuberculosis in New York City. An analysis by DNA fingerprinting and conventional epidemiological methods. New England Journal of Medicine, 330: 1710-1716.

5. Small PM, Hopewell PC, Singh SP, Paz A, Parsonnet J, Ruston DC, Schecter GF, Daley CL \& Schoolnik GK (1994). The epidemiology of tuberculosis in San Francisco. A population-based study using conventional and molecular methods. New England Journal of Medicine, 330: 1703-1709.
6. Small PM, Shafer RW, Hopewell PC, Singh SP, Murphy MJ, Desmond E, Sierra MF \& Schoolnik GK (1993). Exogenous reinfection with multidrug-resistant $M y$ cobacterium tuberculosis in patients with advanced HIV infection. New England Journal of Medicine, 328: 1137-1144.

7. Van Embden JD, Cave MD, Crawford JT, Dale JW, Eisenach KD, Gicquel B, Hermans P, Martin C, McAdam R, Shinnick TM \& Small PM (1993). Strain identification of Mycobacterium tuberculosis by DNA fingerprinting: recommendations for a standardized methodology. Journal of Clinical Microbiology, 31: 406-409.

8. Suffys PN, Ivens de Araujo ME \& Degrave WM (1997). The changing face of the epi- 
demiology of tuberculosis due to molecular strain typing - a review. Memórias do Instituto Oswaldo Cruz, 92: 297-316.

9. Kritski AL, Werneck-Barroso E, Vieira MA, Carvalho AC, Bravo-De-Souza R, Andrade GN, Galvão-Castro B, Castilho EA \& Hearst N (1993). HIV infection in 567 active tuberculosis patients in Brazil. Journal of AIDS, 6: 1008-1012.

10. Hermans PW, Van Soolingen D, Dale JW, Schuitema AR, McAdam RA, Catty D \& Van Embden JD (1990). Insertion element IS986 from Mycobacterium tuberculosis: a useful tool for diagnosis and epidemiology of tuberculosis. Journal of Clinical Microbiology, 28: 2051-2058.
11. Tabet SR, Goldbaum GM, Hooton TM, Eisenach KD, Cave MD \& Nolan CM (1994). Restriction fragment length polymorphism analysis detecting a community tuberculosis outbreak among persons infected with human immunodeficiency virus. Journal of Infectious Diseases, 169: 189-192.

12. Hermans PW, Messadi F, Guebrexabher $H$, van Soolingen $D$, de Haas PE, Heersma $\mathrm{H}$, de Neeling $\mathrm{H}$, Ayoub A, Portaels $\mathrm{F}$, Frommel D, Zribi $M$ \& Van Embden $J$ (1995). Usefulness of DNA typing for global tuberculosis epidemiology. Journal of Infectious Disease, 171: 1504-1513.

13. Yang ZH, Mtoni I, Chonde M, Mwasekaga
M, Fuursted K, Askgard DS, Bennedsen $J$, De Haas PE, Van Soolingen D, Van Embden JD \& Andersen AB (1995). DNA fingerprinting and phenotyping of Mycobacterium tuberculosis isolates from human immunodeficiency virus (HIV)-seropositive and HIV-seronegative patients in Tanzania. Journal of Clinical Microbiology, 33 : 1064-1069.

14. Sechi LA, Zanetti S, Delogu G, Montinaro B, Sanna A \& Fadda G (1996). Molecular epidemiology of Mycobacterium tuberculosis strains isolated from different regions of Italy and Pakistan. Journal of Clinical Microbiology, 34: 1825-1828. 